\title{
Toxicity of various silver nanoparticles compared to silver ions in Daphnia magna
}

\author{
Saba Asghari ${ }^{1,2}$, Seyed Ali Johari, ${ }^{1,2}$, Ji Hyun Lee ${ }^{2}$, Yong Seok Kim², Yong Bae Jeon², Hyun Jung Choi², \\ Min Chaul Moon ${ }^{2}$ and II Je Yü ${ }^{2,3^{*}}$
}

\begin{abstract}
Background: To better understand the potential ecotoxicological impacts of silver nanoparticles released into freshwater environments, the Daphnia magna 48-hour immobilization test was used.

Methods: The toxicities of silver nitrate, two types of colloidal silver nanoparticles, and a suspension of silver nanoparticles were assessed and compared using standard OECD guidelines. Also, the swimming behavior and visible uptake of the nanoparticles by Daphnia were investigated and compared. The particle suspension and colloids used in the toxicity tests were well-characterized.

Results: The results obtained from the exposure studies showed that the toxicity of all the silver species tested was dose and composition dependent. Plus, the silver nanoparticle powders subsequently suspended in the exposure water were much less toxic than the previously prepared silver nanoparticle colloids, whereas the colloidal silver nanoparticles and $\mathrm{AgNO}_{3}$ were almost similar in terms of mortality. The silver nanoparticles were ingested by the Daphnia and accumulated under the carapace, on the external body surface, and connected to the appendages. All the silver species in this study caused abnormal swimming by the D. magna.
\end{abstract}

Conclusion: According to the present results, silver nanoparticles should be classified according to GHS (Globally Harmonized System of classification and labeling of chemicals) as "category acute 1" to Daphnia neonates, suggesting that the release of nanosilver into the environment should be carefully considered.

Keywords: Daphnia magna, Silver, Nanoparticle, Colloid, lon, Acute toxicity

\section{Introduction}

The increasing commercial application of engineered nanomaterials currently shows inventory listings of 1317 nanotechnology-based consumer products in 30 countries [1], plus the production of engineered nanoparticles is expected to reach approximately 60,000 tons in 2011 [2]. Silver is the most important nanomaterial mentioned in consumer product inventories, with 313 products (55.40\% of all nano-products) [1], where the importance of nano-silver (nAg) is due to its antimicrobial properties [3-6] and application in the fields of material science, chemistry and physics. However, with the increasing presence of manufactured nanomaterials in consumer products, large quantities of nanoparticles could be released and eventually enter aquatic

\footnotetext{
* Correspondence: u1670916@chollian.net

${ }^{2}$ Institute of Nanoproduct Safety Research, Hoseo University, Asan, Korea Full list of author information is available at the end of the article
}

ecosystems, either wittingly or by chance [7-10], posing serious possible risks to the environment. Therefore, investigating the potential aquatic toxicity of nanomaterials has become an important issue.

Daphnia magna, a freshwater filter-feeding crustacean, is one of the most sensitive organisms used in ecotoxicity experiments and a standard test organism for the standard protocols of the U.S. Environmental Protection Agency (EPA), Organization for Economic Cooperation and Development (OECD), and International Standards Organization (ISO) $[11,12]$. Furthermore, since $D$. magna is at the bottom of the food chain in freshwater aquatic ecosystems, any change in its population quality or quantity can result in changes in the populations of other aquatic organisms. Even though the toxicity of AgNPs has already been studied in aquatic organisms such as Daphnia [13-16], the distinct characteristics of nanoparticles (e.g. preparation method, kind of capping
C Biomed Central

() 2012 Asghari et al; licensee BioMed Central Ltd. This is an Open Access article distributed under the terms of the Creative Commons Attribution License (http://creativecommons.org/licenses/by/2.0), which permits unrestricted use, distribution, and reproduction in any medium, provided the original work is properly cited. 
agent, size, and shape) may change their effect on living organisms, leading some scientists to suggest that the toxicity of these new materials needs to be investigated case by case. Accordingly, the present study used $D$. magna as a model aquatic organism to evaluate the short-term toxicity of three different types of well-characterized silver nanoparticles, including two nano-Ag colloids, one of which has already been supplied as a reference material for the OECD WPMN (working party on manufactured nanomaterials) sponsorship programme on the testing of manufactured nanomaterials, and a nano-Ag powder suspended in water by sonication; moreover, an $\mathrm{AgNO}_{3}$ solution was also used to compare the toxicity effects of silver ions and silver nanoparticles. For each type of material, the mortality and immobilization rates, swimming type, and visible uptake of nanoparticles by Daphnia were investigated and compared.

\section{Materials and methods}

\section{Nanoparticles and characterization}

The present study used two types of colloidal silver nanoparticles and a suspension of silver nanoparticles as the sources of nanoparticles; plus, $\mathrm{AgNO}_{3}$ was used as the source of silver ions.

The first type of colloidal silver nanoparticles was donated by ABC Nanotech Co., LTD (Daejeon, Korea). The name of this blackish-brown product was SARPU $200 \mathrm{KW}$ and, according to the information provided by the manufacturer, it was a water-based colloid containing $200000 \mathrm{mg} / \mathrm{L}$ spherical silver nanoparticles (5-25 $\mathrm{nm})$. The purity of the silver nanoparticles was defined as $99.98 \%$. The product was also extensively characterized and found to contain 20.48 wt\% silver nanoparticles (thermogravimetry, TGA851, Mettler Toledo, Swiss) and $1.0 \mathrm{wt} \%$ citrate as the capping agent (HPLC, Waters 2690 analyzer) at pH 5.80. These silver nanoparticles have also been supplied as a reference material for the OECD WPMN sponsorship programme. Hereinafter, this colloid will be referred to as nAg1.

The second type of colloidal silver nanoparticles was purchased from Nano Nasb Pars Co., Ltd (Tehran, Iran). The name of this yellowish-brown product was Nanocid L2000 and, according to the information provided by the manufacturer, it was a water-based colloid containing $4000 \mathrm{mg} / \mathrm{L}$ spherical silver nanoparticles (average size $16.6 \mathrm{~nm}$ ). The colloid product was synthesized using a novel process involving the photo-assisted reduction of $\mathrm{Ag}^{+}$to metallic nanoparticles, registered under United States Patent Application No: 20090013825. Briefly, $4.5 \mathrm{~g}$ of LABS (Linear alkyl benzene sulfonate) was dissolved in $95 \mathrm{ml}$ of distilled water and then added to a solution containing $0.32 \mathrm{~g}$ of silver nitrate. After mixing thoroughly, $0.2 \mathrm{~g}$ of a hydrazine solution $(0.03 \mathrm{M})$ was added, resulting in the formation of a yellowish silver colloidal solution. The measured $\mathrm{pH}$ of this product was 2.4, and some of its other properties were characterized in this study. Hereinafter, this colloid will be referred to as nAg2.

The powdered silver nanoparticles were purchased from Xuzhou Hongwu Nanometer Material Co., Ltd (Jiangsu, China). According to the information provided by the manufacturer, this black powder was $99 \%$ pure spherical silver nanoparticles with an average size of 20 $\mathrm{nm}$. A stock suspension of $400 \mathrm{mg} / \mathrm{L}$ was prepared by dispersing $40 \mathrm{mg}$ of this powder in $100 \mathrm{ml}$ distilled deionized water, followed by vigorous vortexing (Thermo Scientific M37610) for $30 \mathrm{~min}$ at room temperature, then sonication for 6 hours in a bath-type sonicator (Branson 8510EXT-0011). Although this suspension was very stable after sonication, it was sonicated for a further $15 \mathrm{~min}$ immediately prior to each dosing. The $\mathrm{pH}$ of the final suspension was 7.32. Hereinafter, this suspension will be referred to as nAg3.

To compare the toxicity of the different silver nanoparticles with that of ionic silver, a stock solution of 400 mg/L $\mathrm{AgNO}_{3}$ (purity > 99.5\%, Fluka chemika, SigmaAldrich, Switzerland) was prepared in distilled deionized water. The $\mathrm{pH}$ of the final solution was 6.43 .

TEM analyses of nAg3 as a dry powder and in suspension, plus the nAg2 colloid were performed using an $\mathrm{H}$ 7100FA transmission electron microscope (Hitachi, Japan) with an acceleration voltage of $125 \mathrm{kV}$. In addition, TEM micrographs of nAg1 (FEI Tecnai G2-20-STWIN) were provided by ABC Nanotech Co., LTD (Daejeon, Korea). For each type of silver nanoparticle, the diameters of 700 randomly selected particles were measured at a magnification of 100,000 using Axio Vision digital image processing software (Release 4.8.2.0, Carl Zeiss Micro Imaging GmbH, Germany). EDX analyses of the dry powder, suspension, and colloids were also performed using an EX200 Energy-dispersive x-ray analyzer (Horiba, Japan).

Absorption spectral measurements were conducted on all the colloids and the suspension using a SpectraMAX-PLUS 384 UV-visible spectrophotometer (Molecular Devices, USA) with a range of 190-1000 $\mathrm{nm}$.

\section{Daphnia acute toxicity tests}

The acute $(48 \mathrm{~h})$ toxicity tests were conducted in accordance with OECD guideline number 202 (Daphnia Sp. acute immobilization test) [12]. In this study, fully aerated M4 media were used as the exposure media and the test solutions were prepared immediately prior to use by diluting the different stocks mentioned above in the M4 media. After adding appropriate amounts of the stocks to the M4 media, the stock mixtures were stirred using a magnetic stirrer to distribute the suspension at as 
stable a concentration as possible. In addition, to avoid significant changes in the concentration of AgNPs during exposure, the media were refreshed every $24 \mathrm{~h}$.

A series of preliminary experiments was conducted to determine the range of chemical concentrations that caused mortality in D. magna. According to the determined concentration ranges, effective concentrations were then selected for each substance (Table 1).

Each test included a completely random design, consisting of ten treatments in triplicate and three control groups. Ten randomly selected neonates (younger than $24 \mathrm{~h}$ old) were placed in $100 \mathrm{ml}$ exposure media in glass exposure beakers. All the tests were conducted in a water bath system with a constant temperature $\left(20 \pm 2^{\circ}\right.$ C) and $16 \mathrm{hr}$ light/ $8 \mathrm{hr}$ dark cycles. Since the presence of algae has been previously shown to affect the toxicity of nanoparticles [13] and the presence of organic matter shown to inhibit silver ion uptake by Daphnia [17], the animals were not fed during the experiments.

After 24 and 48 hours of exposure, the immobilization and mortality of the Daphnia in each test beaker were assessed using an Olympus CX41 microscope equipped with a digital camera (DIXI 3000 mega pixels, NEK Corp, Germany). According to Annex 1 of OECD 211, an animal was recorded as dead when it was immobile, i.e. not able to swim or no observed movement of appendages or the post-abdomen within 15 seconds after gentle agitation of the test container [18].

Furthermore, the live Daphnia were categorized in one of the following groups according to their swimming type: normal swimming (NOR), erratic swimming (ERR), Daphnia mainly at the bottom (BOT), and Daphnia mainly at the surface (SUR). Plus, any visible uptake and adsorption of nanomaterials by the D. magna were monitored and recorded.

\section{Statistical analysis}

The 48-h EC10, EC50, and EC90 values, as well as their associated 95\% confidence intervals (95\% CI) were calculated using the US EPA Probit Analysis Program (version 1.5). In required cases, statistical analyses were carried out using standard ANOVA techniques, followed by Tukey's significant difference test (SPSS Ver. 17.0). Differences were statistically significant when $\mathrm{p}<0.05$. The particle size distributions of the three types of silver nanoparticle were statistically compared using a MannWhitney rank sum test.

\section{Results}

\section{Particle characterization}

In the nAg1 colloid observed by TEM, the particles were spherical in shape (Figure 1A), with a maximum diameter of $15.83 \mathrm{~nm} ; 36.06 \%$ of the particles had diameters between 7 and $9 \mathrm{~nm}$ (Figure 2A); and the CMD (count median diameter) for the particles was $7.32 \mathrm{~nm}$ (Figure 3A). Also, the geometric mean diameter (GMD) and geometric standard deviation (GSD) of the colloidal silver nanoparticles were $7.96 \mathrm{~nm}$ and 1.35 , respectively.

In the case of the nAg2 colloid observed by TEM, the particles were spherical in shape (Figure 1B), with a maximum diameter of $129 \mathrm{~nm}$ : $65.14 \%$ of the particles had diameters between 1 and $13 \mathrm{~nm}$ (Figure 2B), just $2.28 \%$ of the particles had diameters more than $100 \mathrm{~nm}$, and the CMD for the particles was $6.47 \mathrm{~nm}$ (Figure 3B). Also, the geometric mean diameter (GMD) and geometric standard deviation (GSD) of the colloidal silver nanoparticles were $12.65 \mathrm{~nm}$ and 1.46, respectively.

In the case of the dry powder of nAg3 observed by TEM, the particles were spherical in shape (Figure 1C), with a maximum diameter of $161 \mathrm{~nm}$ : $85.97 \%$ of the particles had diameters between 1 and $45 \mathrm{~nm}$ (Figure $2 \mathrm{C}$ ), just $1.34 \%$ of the particles had diameters more than $100 \mathrm{~nm}$, and the CMD for the particles was $17.97 \mathrm{~nm}$ (Figure 3C). Also, the GMD and GSD of the dry powdered silver nanoparticles were $14.39 \mathrm{~nm}$ and 1.31, respectively. In the case of the $\mathrm{nAg} 3$ suspension, despite extensive sonication, the TEM images showed that in an aqueous environment about $52.9 \%$ of the nanoparticles were clumped together and formed large aggregates (Figure 1D). About $70.31 \%$ of the aggregates had diameters from 25 to $100 \mathrm{~nm}$, while most of the others had diameters from 100 to about $250 \mathrm{~nm}$.

The particle size distributions of the three types of silver nanoparticle were statistically compared using a Mann-Whitney rank sum test. Statistically significant differences were found among the particle size distributions $(\mathrm{P}<0.001$, nAg1 vs. nAg2; $\mathrm{P}<0.001$, nAg1 vs. nAg3; $\mathrm{P}<0.001$, nAg2 vs. nAg3). Thus, while the CMDs for $\mathrm{nAg} 1$ and $\mathrm{nAg} 2$ were similar, the distributions were different.

Table 1 Concentration gradients of different nanoparticles and $\mathrm{AgNO}_{3}$ used for acute toxicity tests (concentration ranges were selected according to preliminary experiments)

\begin{tabular}{ccccccccccc}
\hline Chemical notation & \multicolumn{10}{c}{ Concentration $(\mathbf{m g} / \mathbf{L})$} \\
\hline $\mathrm{nAg} 1$ colloid & 0.001 & 0.002 & 0.003 & 0.004 & 0.005 & 0.006 & 0.007 & 0.008 & 0.009 & 0.01 \\
\hline $\mathrm{nAg} 2$ colloid & 0.001 & 0.0012 & 0.0015 & 0.0017 & 0.002 & 0.0022 & 0.0025 & 0.0027 & 0.003 & 0.0032 \\
\hline $\mathrm{nAg3}$ suspension & 0.1 & 0.125 & 0.150 & 0.175 & 0.2 & 0.225 & 0.25 & 0.275 & 0.3 & 0.32 \\
\hline $\mathrm{AgNO}_{3}$ solution & 0.001 & 0.0012 & 0.0015 & 0.0018 & 0.0021 & 0.0024 & 0.0027 & 0.0029 & 0.0032 & 0.0034 \\
\hline
\end{tabular}



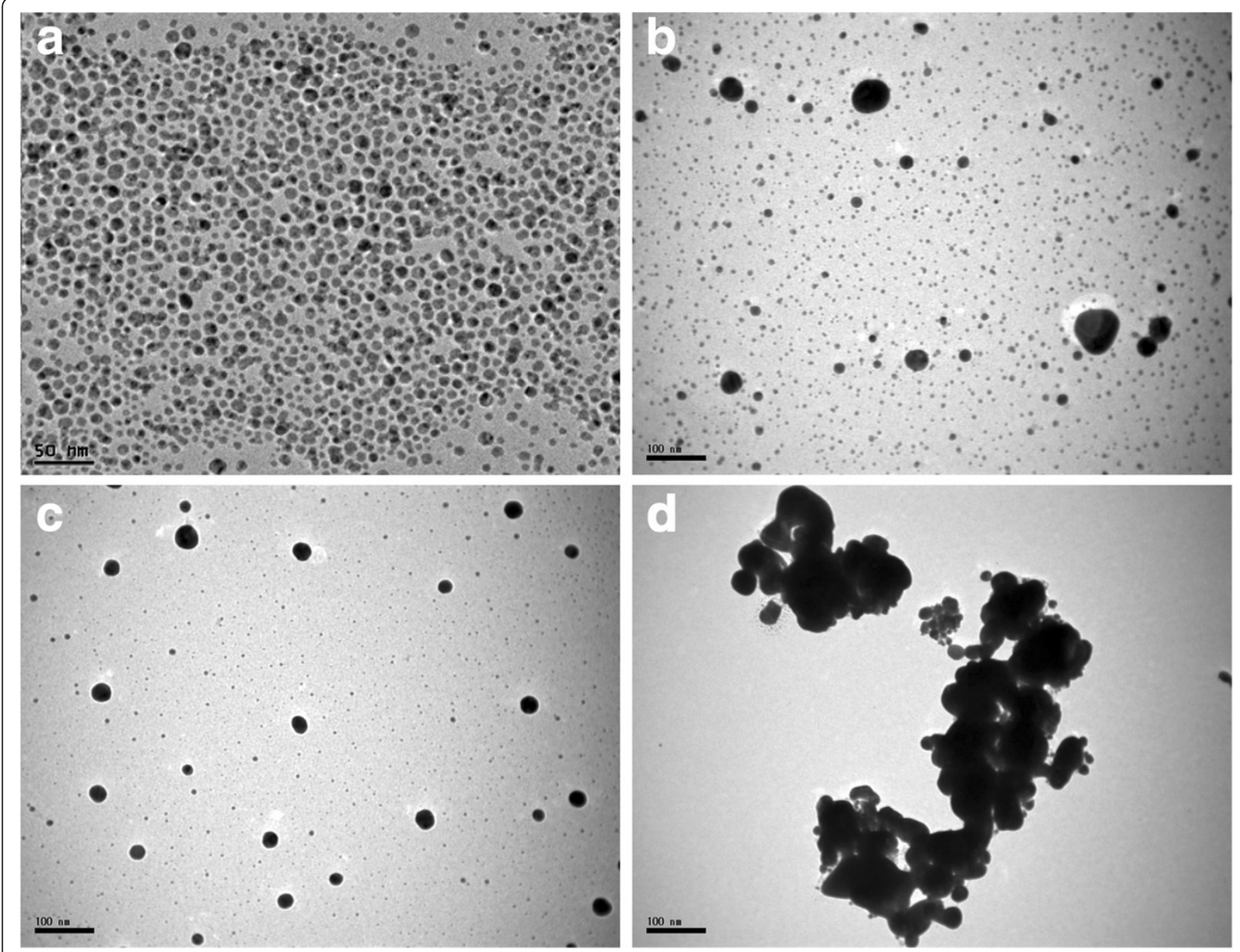

Figure 1 TEM micrographs of different nanoparticles: (A) nAg1 colloid, (B) nAg2 colloid, (C) dry powder of nAg3, and (D) suspension of $n A g 3$.

As seen in Figure 4, the EDX analyses revealed the presence of elemental silver in the nAg2 colloid and nAg3 preparation.

In the spectral scans of the nAg1 and nAg2 colloids, a strong surface plasmon resonance was centered at approximately 420 and $410 \mathrm{~nm}$, respectively (Figure 5), which is similar to previous results for AgNPs [5,19-21]. However, for the nAg3 suspension, $\mathrm{AgNO}_{3}$ solution, and distilled water, no distinct peaks were observed (Figure 5). The observation of a strong surface plasmon peak has already been well documented for various metal nanoparticles, with sizes ranging from 2 to $100 \mathrm{~nm}[22,23]$. In the case of nAg3, the increase in the particle size to more than $100 \mathrm{~nm}$ through aggregation may have been the reason for the lack of appearance of a distinct peak.

\section{Determination of effective concentrations (EC)}

During the experiments, the mean and SD of the water $\mathrm{pH}$ and dissolved oxygen in the exposure vessels were
$7.81 \pm 0.13$ and $7.44 \pm 0.19 \mathrm{mg} / \mathrm{L}$, respectively. Also, there was no significant difference between treatments in this regard $(\mathrm{P}>0.05)$.

The nAg1 and nAg2 colloids (Figure 6) remained very stable in the exposure media (confirmed by UV-vis spectrophotometry, data not shown), and there were no signs of precipitation of the nanoparticles in the test beakers. In the case of the suspension of nAg3, sediments of aggregated nanoparticles became gradually visible at the bottom of the test beakers with the elapse of time; nonetheless, after 24 hours (and before refreshing the exposure media), most of the nAg3 particles were still suspended in the water (Figure 6).

During the exposure period, the mortality in the control groups was less than $5 \%$ for all the tests. The lowest concentrations of $\mathrm{nAg} 1, \mathrm{nAg} 2, \mathrm{nAg} 3$, and $\mathrm{AgNO}_{3}$ that caused $100 \%$ mortality of Daphnia after 48 hours were $0.006,0.00325,0.275$, and $0.0032 \mathrm{mg} / \mathrm{L}$, respectively. Also, the highest concentrations of nAg1, 

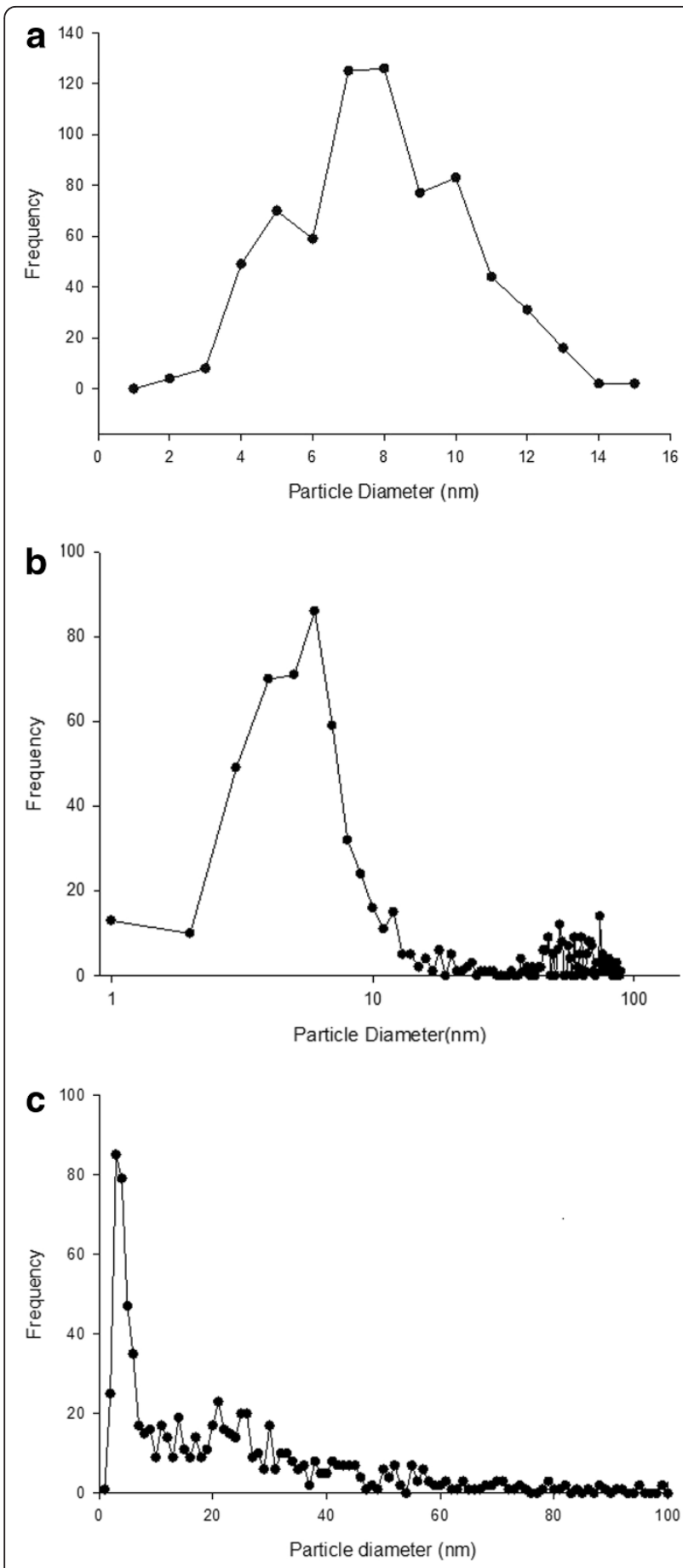

Figure 2 Size distribution of particles based on number frequency determined from transmission electron microscope data in: (A) nAg1 colloid, (B) nAg2 colloid, (C) and dry powder of $n A g 3$.

nAg2, nAg3, and $\mathrm{AgNO}_{3}$ that did not cause any mortality of Daphnia during 48 hours were $0.002,0.001$, 0.1 , and $0.0015 \mathrm{mg} / \mathrm{L}$, respectively. The average values of the effective concentrations and their 95\%
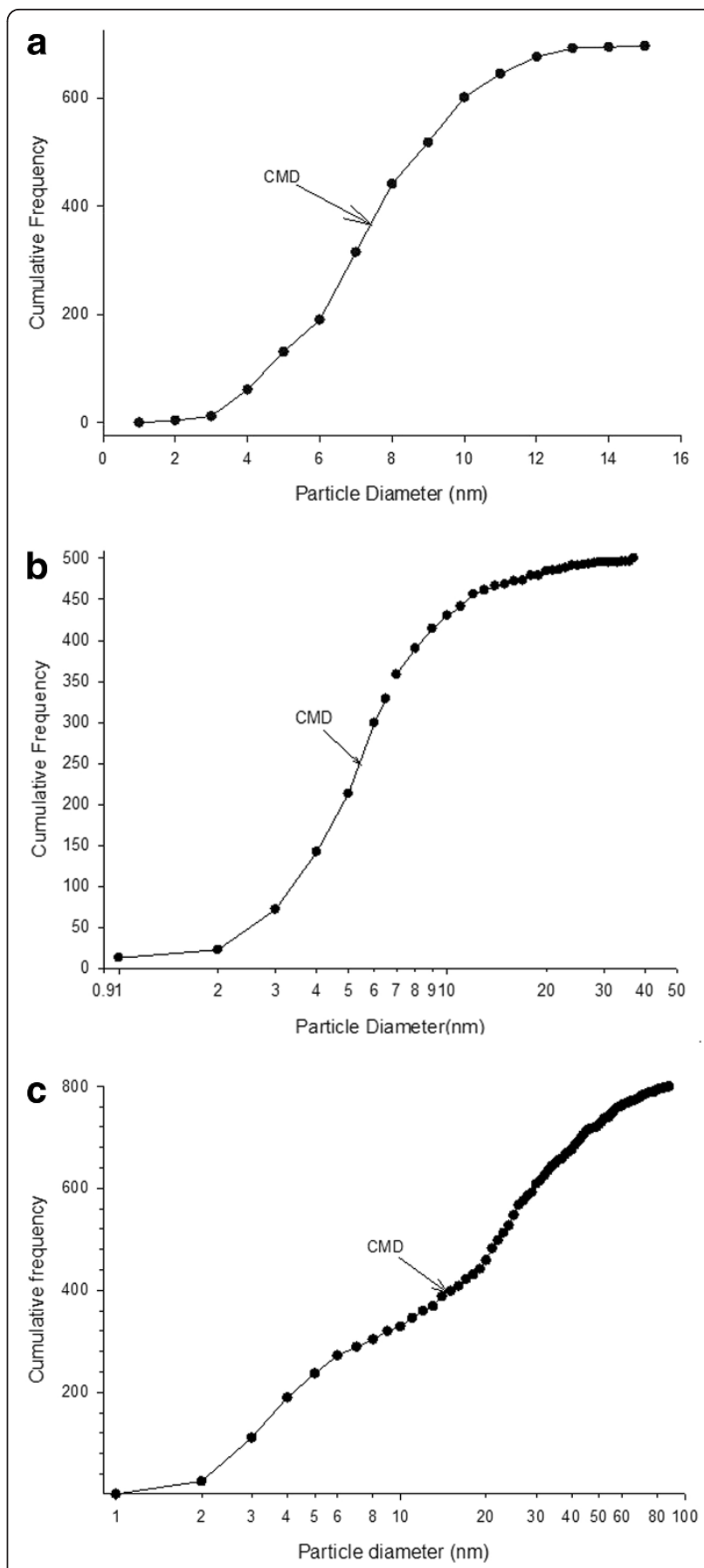

Figure 3 Size distribution of particles based on cumulative frequency determined from transmission electron microscope data in: (A) nAg1 colloid, (B) nAg2 colloid, (C) and dry powder of $\mathrm{nAg}$. Statistically significant differences were found among particle size distributions $(P<0.001, \mathrm{nAg} 1$ vs nAg2; $P<0.001, \mathrm{nAg} 1$ vs nAg3; $P<0.001, \mathrm{nAg} 2$ vs nAg3).

confidence limits are shown in Table 2. The median effective concentrations of $\mathrm{nAg} 1, \mathrm{nAg} 2, \mathrm{nAg} 3$, and $\mathrm{AgNO}_{3}$ were calculated as $0.004,0.002,0.187$, and $0.0023 \mathrm{mg} / \mathrm{L}$, respectively. 

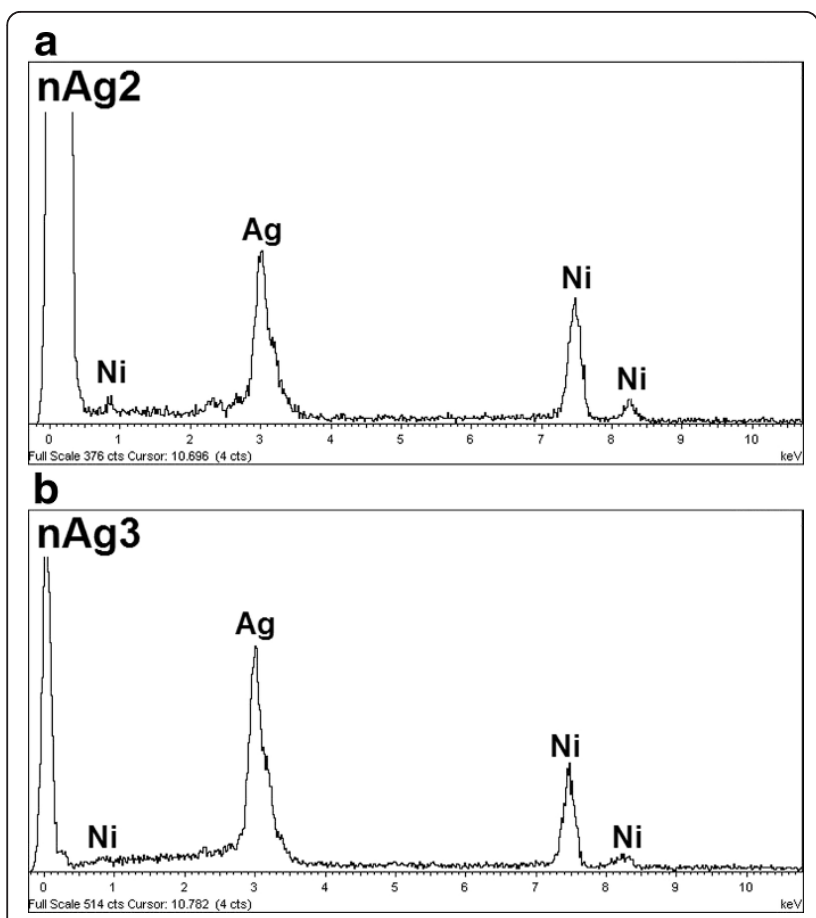

Figure 4 EDX spectrometer patterns of $n A g 2$ and $n A g 3$; $(\mathrm{Ni}$ signals in EDX spectrometer are from TEM grid)

\section{Uptake and adsorption of NPs}

After exposing the Daphnia to the nAg1 and nAg2 colloids and the nAg3 suspension, some pigmentation became visible in parts of the brood chamber that was not observed with the $\mathrm{AgNO}_{3}$ treatments and in the controls (Figures 7, 8); this pigmentation may have been a sign of nanoparticle accumulation under the carapace. In addition, at higher concentrations, nanoparticle aggregates were seen to be attached to the external body surface and appendages of the D. magna (Figures

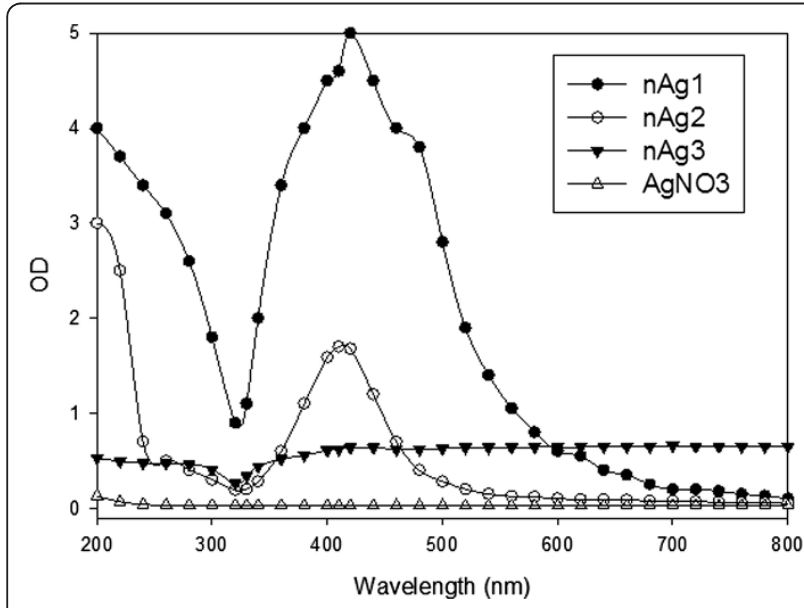

Figure 5 UV-VIS absorption spectra for colloids of $\mathrm{nAg} 1$ and $\mathrm{nAg2}, \mathrm{nAg} 3$ suspension, and $\mathrm{AgNO}_{3}$ solution.

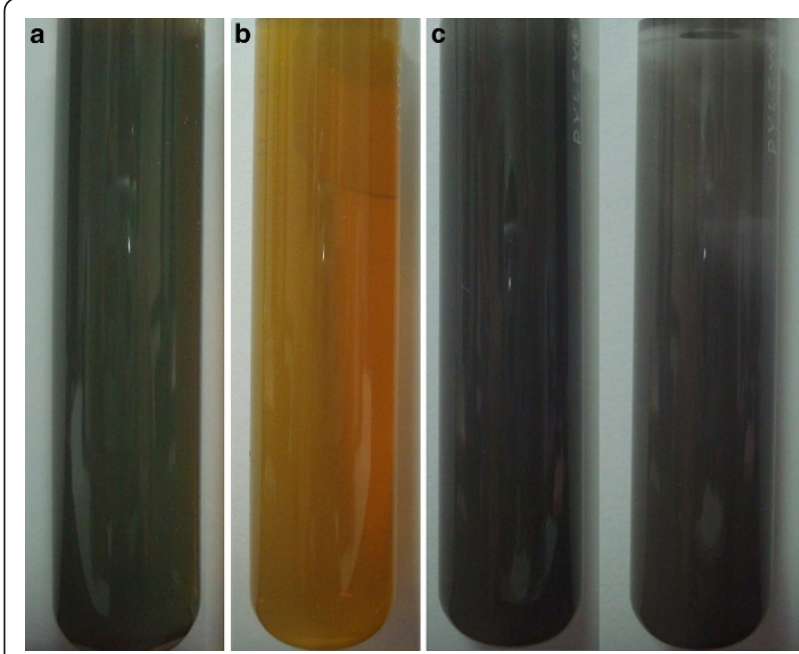

Figure 6 Photograph comparing appearance of aqueous stocks of nanoparticles $(400 \mathrm{mg} / \mathrm{L})$ used for toxicity tests. $A: n A g 1$ colloid; $\mathbf{B}: \mathrm{nAg} 2$ colloid; $\mathbf{C}$ : suspensions of nAg3 before (left) and after (right) 24 hours.

$7,8)$, which in some cases affected the swimming ability. Also, a notable phenomenon with the colloidal treatments (nAg1 and nAg2) was the appearance of small bubbles under the carapace of the Daphnia (Figure 7).

With the nAg3 treatments, large amounts of a dark material were found in the gut tract of the Daphnia after nanoparticle exposure (Figure 8); thus, the nAg3 tested in this study was clearly ingested by the $D$. magna, resulting in accumulation in the gut. In some cases, the ingestion of the particles was enough to prevent the movement of the Daphnia through the water column and caused them to sink to the bottom of the beakers.

\section{Effects on swimming behavior}

The normal and abnormal swimming of the live Daphnia are summarized in Table 3. In all the control groups, $100 \%$ of the live Daphnia exhibited completely normal swimming. In the case of abnormalities following exposure to the silver compounds, in the early stages, the Daphnia showed erratic swimming (ERR), while in the later stages, they migrated to the bottom (BOT) of the beaker or the water surface (SUR).

In the nAg1 treatments, at concentrations up to 0.001 $\mathrm{mg} / \mathrm{L}, 100 \%$ of the live Daphnia exhibited normal swimming; yet at higher concentrations $(0.002 \mathrm{mg} / \mathrm{L}$ and more), all the Daphnia exhibited abnormal swimming. More than $90 \%$ of the abnormalities in the nAg1 groups were related to ERR.

About 26.6 to $51.3 \%$ of the live Daphnia in the nAg2 treatments exhibited abnormal swimming, yet the abnormalities were not dose dependent. Most of the 
Table 2 Effective-concentration values, with lower and upper $95 \%$ confidence limits (CL), of different nanoparticles and $\mathrm{AgNO}_{3}$ for Daphnia magna neonates during $48 \mathrm{~h}$

\begin{tabular}{cccc}
\hline Chemical notation & $\begin{array}{c}\text { Average EC10 (95\%CL) } \\
(\mathbf{m g} / \mathbf{L})\end{array}$ & $\begin{array}{c}\text { Average EC50 (95\%CL) } \\
(\mathbf{m g} / \mathbf{L})\end{array}$ & $\begin{array}{c}\text { Average EC90 (95\%CL) } \\
(\mathbf{m g} / \mathbf{L})\end{array}$ \\
\hline nAg1 colloid & 0.003 & 0.004 & 0.005 \\
& $(0.003-0.003)$ & $(0.004-0.004)$ & $(0.004-0.005)$ \\
\hline nAg2 colloid & 0.0015 & 0.002 & 0.003 \\
& $(0.001-0.002)$ & $(0.002-0.002)$ & $(0.003-0.003)$ \\
\hline nAg3 suspension & 0.140 & 0.187 & 0.251 \\
& $(0.110-0.158)$ & $(0.165-0.205)$ & $(0.226-0.301)$ \\
\hline AgNO$_{3}$ solution & 0.0017 & 0.0023 & 0.0031 \\
& $(0.0015-0.0018)$ & $(0.0022-0.0024)$ & $(0.0031-0.0037)$ \\
\hline
\end{tabular}

abnormal Daphnia in order of frequency were BOT and SUR; and no ERR was observed in these groups.

In the case of the nAg3 treatments, about 26.3 to $31 \%$ of the live Daphnia exhibited abnormal swimming, yet the percentage of abnormalities did not differ significantly between the different concentrations $(\mathrm{P}>0.05)$. In the lowest concentration $(0.1 \mathrm{mg} / \mathrm{L})$, most of the abnormal Daphnia were ERR, yet in the higher concentrations (0.125 mg/L and more), the abnormal Daphnia were BOT and SUR, respectively.

In the $\mathrm{AgNO}_{3}$ treatments, the percentage of abnormalities was dose dependent, and differed from $6.6 \%$ in the lowest concentration (0.001) up to $100 \%$ in the highest concentrations. Also, most of the abnormal Daphnia were BOT and SUR; and no ERR was observed in these groups.

\section{Discussion}

The results of the present study demonstrated that silver nanoparticles are capable of causing acute toxicity in $D$. magna; however, the toxicity differed significantly according to the particle type. Several mechanisms have already been suggested to explain the toxic effect of silver nanoparticles; the presence of the nanoparticles themselves, the release of $\mathrm{Ag}^{+}$from nanoparticles, and the free radicals generated during dissolution in an AgNP suspension [24-28].

The 48-hour EC50 of the nAg3 suspension (nano silver powder) was determined to be $0.187 \mathrm{mg} / \mathrm{L}$, which was relatively close to the results of Gaiser et al. [14] who previously reported that the EC50 of a sonicated nano-Ag suspension ( $588 \mathrm{~nm}$ average diameter of aggregates) was about $0.1 \mathrm{mg} / \mathrm{L}$. Thus, the $\mathrm{nAg} 3$ was about 47 times less toxic than the nAg1 colloid and about 93 times less toxic than the nAg2 colloid. In previous literature on the toxicity of silver nanoparticles to Daphnia [13-16], the acute toxicity of laboratory-synthesized and ready-for-use silver nanoparticle suspensions (48-hour EC50 = 0.001- 0.003 $\mathrm{mg} / \mathrm{L}$ ) was higher than that of nano powders subsequently suspended in exposure water using sonication or agitation (48-hour EC50 = 0.031-0.1 mg/L). One possible explanation is that, in the case of nano powders that are subsequently suspended (as with nAg3 in the present study), despite the application of sonication, most of the particles tend to form aggregates and make large clumps in aqueous media, thereby decreasing the surface area to volume ratio and reducing the toxicity compared to the ready-for-use AgNP solutions. One exception to this is the study by Park and Choi [29], who showed that the lethal concentration of suspended powder AgNPs for Daphnia was about 0.001 to $0.002 \mathrm{mg} / \mathrm{L}$, however, their study used a long sonication time (13 hours), followed by stirring for seven days and filtering through a $100 \mathrm{~nm}$ membrane; thus, a possible explanation for their high toxicity result was the dissolution of the silver ions into the aqueous media during the 7 days of stirring. In this regard, Kittler et al. [30] showed that the toxicity of AgNPs to human mesenchymal stem cells increased during storage due to the release of silver ions into the stock suspension.

The EC50 of the nAg2 colloid was determined to be $0.002 \mathrm{mg} / \mathrm{L}$, which matched the results of Kennedy et al. [16], who reported that the EC50 of a $31 \mathrm{~nm}$ nano-Ag colloid (ASAP ${ }^{\circledR}$ ) was $0.0018 \mathrm{mg} / \mathrm{L}$. Meanwhile, the EC50 of the nAg1 colloid was determined to be $0.004 \mathrm{mg} / \mathrm{L}$, so this colloid was two times less toxic than the nAg2 colloid. Even though the particle sizes of the nAg1 and nAg2 colloids were relatively similar (most particles were under $20 \mathrm{~nm}$ ), the size distribution was significantly different. Thus, it is likely that other distinct characteristics of these two nano-Ag colloids were also related to the different toxicities, along with the particle size difference. For example, different coating agents may have led to the different toxicities. In this regard, Kennedy et al. [16] showed that the toxicities of various AgNPs with different coating agents (Citrate, EDTA, and Polyvinylpyrrolidone) were different (EC50 ranges were 0.0054-0.097 mg/L). Similarly, Zhao and Wang [31] showed that the EC50s of AgNPs with lactate, polyvinylpyrrolidone, and sodium dodecylbenzene sulfonate coatings were $0.0287,0.002$, and $0.0011 \mathrm{mg} / \mathrm{L}$, respectively, for seven-day old D. magna. Also, Allen et al. 

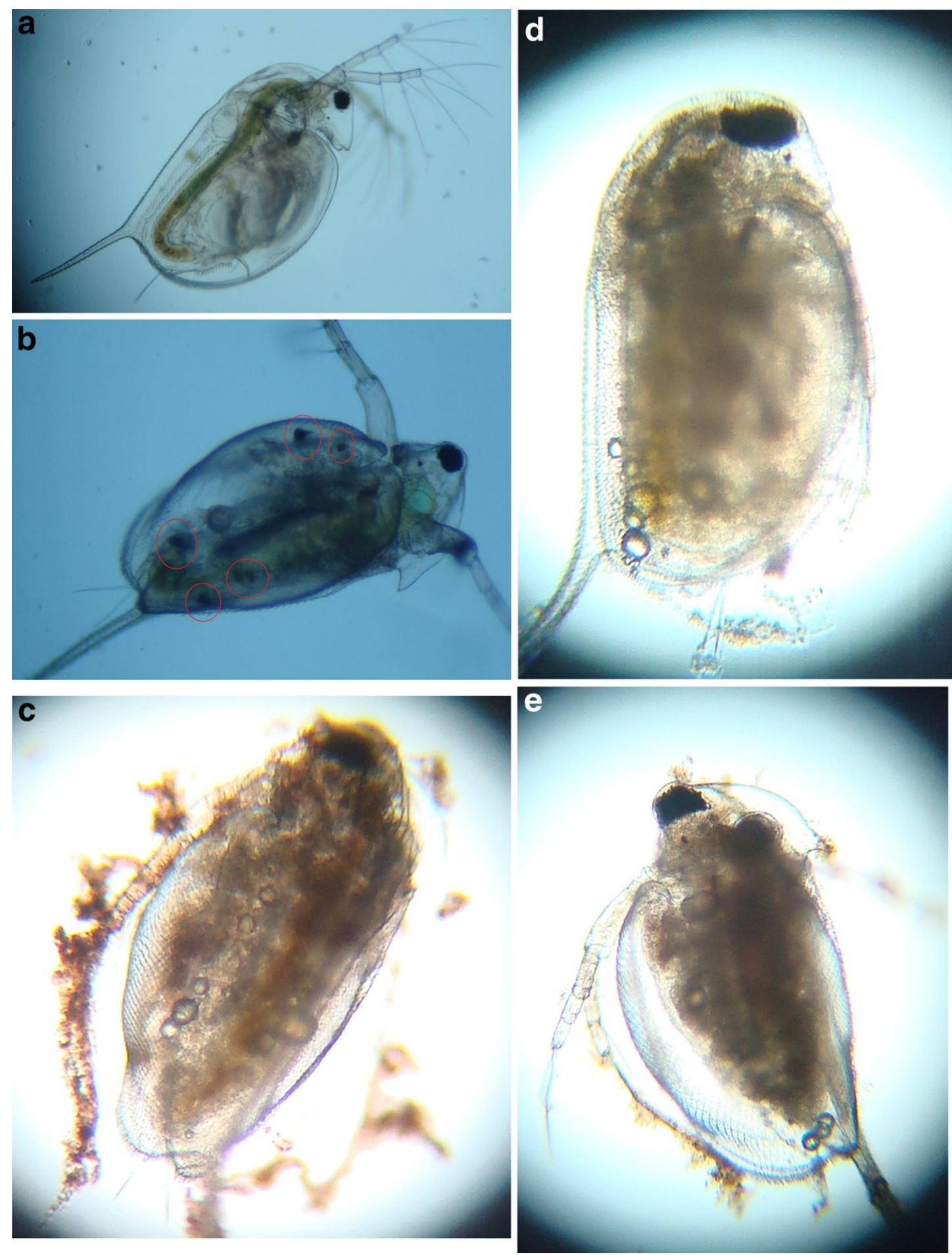

Figure $\mathbf{7}$ Light microscope images of daphnia exposed to $\mathrm{nAg} \mathbf{1}$ and $\mathbf{n A g} 2$ colloids for $\mathbf{2 4}$ hours. A: control; B: live daphnia exposed to $0.002 \mathrm{mg} / \mathrm{L} \mathrm{nAg1,} \mathrm{pigmentation} \mathrm{can} \mathrm{been} \mathrm{seen} \mathrm{under} \mathrm{the} \mathrm{brood} \mathrm{chamber} \mathrm{(circles);} \mathrm{C:} \mathrm{dead} \mathrm{daphnia} \mathrm{exposed} \mathrm{to} 0.01 \mathrm{mg} / \mathrm{L} \mathrm{nAg} 2 ; \mathbf{D}$ : live daphnia exposed to $0.004 \mathrm{mg} / \mathrm{L} \mathrm{nAg1;}$ E: live daphnia exposed to $0.002 \mathrm{mg} / \mathrm{L} \mathrm{nAg2.} \mathrm{In} \mathrm{images} \mathrm{C,} \mathrm{D,} \mathrm{and} \mathrm{E,} \mathrm{small} \mathrm{bubbles} \mathrm{can} \mathrm{be} \mathrm{seen} \mathrm{under} \mathrm{the}$ carapace; plus, nanoparticle aggregates can be seen on the antennae, body surface, and also in the brood chamber. 

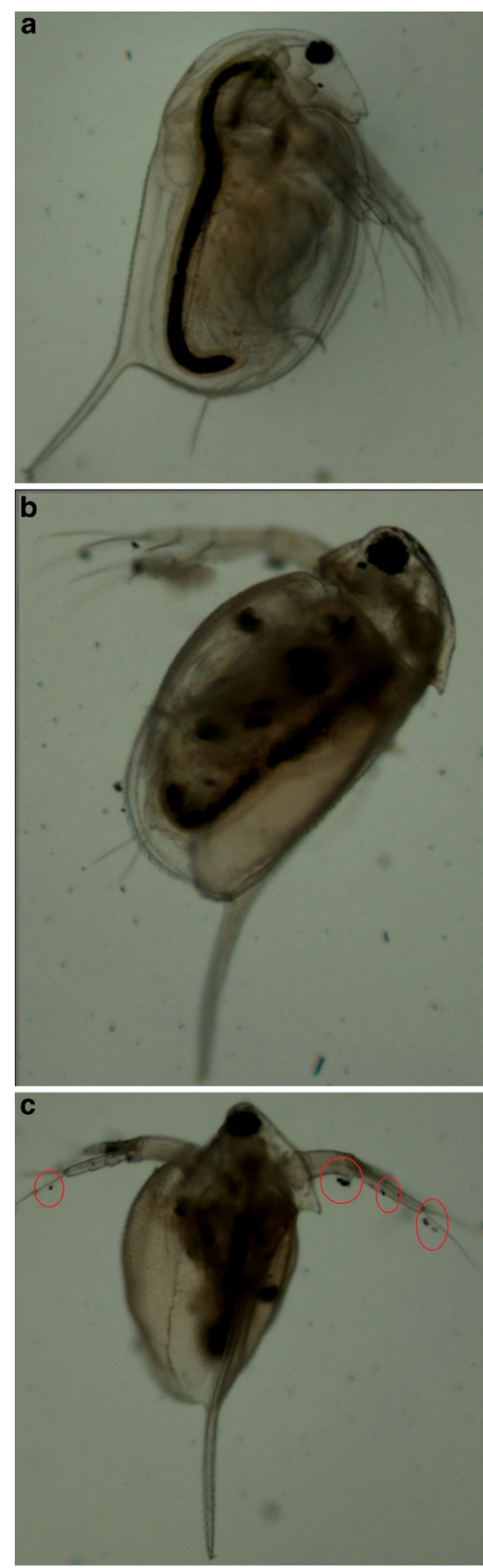

Figure 8 D. magna after 24-hour exposure to $0.15 \mathrm{mg} / \mathrm{L}$ aqueous suspension of $\mathbf{n A g 3}$. A: black color of digestive tract shows uptake of nAg3. $\mathbf{B}$ and $\mathbf{C}$ : nanoparticle aggregates are attached to antennae and also seen in brood chamber.
[13] showed that the toxicity of uncoated particles was slightly higher than that of coated particles, and the toxicity of filtered suspensions was higher than that of unfiltered suspensions for D. magna.

The 48-hour EC50 for the silver ions $\left(\mathrm{AgNO}_{3}\right)$ was determined to be $0.0023 \mathrm{mg} / \mathrm{L}$, which matched well with previous literature [32-34]. Although, lower EC50s (0.0003, 0.0007, 0.0009, 0.0011, and 0.0016) have been reported in some other studies using Daphnia [13,16,31,35-37]. These differences in the toxicity thresholds may have been related to differences in the chemical purity, animal sensitivity, or test designs. In contrast, the EC50 value for $\mathrm{nAg} 2$ was relatively similar to that for $\mathrm{AgNO}_{3}$.

Overall, the comparative toxicity results for the different $\mathrm{AgNPs}$ and $\mathrm{AgNO}_{3}$ used in the current study suggest that silver nano powders subsequently suspended in exposing water are much less toxic than previously prepared nano Ag colloids, while colloidal AgNPs and silver nitrate are almost identical in terms of their toxicity.

Generally, EC50 data provides a good baseline for toxicity tests. According to GHS (Globally harmonized system of classification and labelling of chemicals, [38]) any substance with a $48 \mathrm{hr}$ LC/EC50 (for Daphnia) of less than $1 \mathrm{mg} / \mathrm{L}$ must be classified as "category acute 1" to aquatic organisms. In addition, European Union legislation [39] and European Union Council Directive 67/ 548/EEC of 27 June 1967 [40] classified as "very toxic. Therefore, according to the present results, all the silver nanoparticle types and silver nitrate tested in the current study should be classified as "category acute 1".

Based on the present results, nAg3 was clearly ingested by the $D$. magna, resulting in accumulation in the gut. Thus, the results suggest that the aquatic exposure of aquatic organisms to such NPs could pose a risk of bioaccumulation, especially for filter-feeding copepods such as D. magna. In this regard, Zhao and Wang [31] showed that Daphnia can retain a large amount of AgNPs in their guts after ingestion. Other studies have also indicated that D. magna can uptake nanomaterials from test solutions [41-50]. Since Daphnia are part of the diet of other organisms, including fish, there is a potential for uptake and the subsequent transfer of nanoparticles to higher organisms.

Unlike the control groups that exhibited normal swimming, the Daphnia exposed to each type of silver compound showed at least one type of abnormality (ERR, BOT, or SUR). According to the results, it seemed that during the early stages of exposure, the Daphnia mostly showed erratic swimming, whereas in the later stages and in higher concentrations, they often migrated 
Table 3 Percentage of normal and abnormal Daphnia magna neonates during 48-hour exposure to different nanoparticles and $\mathrm{AgNO}_{3}$

\begin{tabular}{|c|c|c|c|c|c|c|}
\hline $\begin{array}{l}\text { Chemical } \\
\text { notation }\end{array}$ & Conc. & $\begin{array}{c}\% \\
\text { normal }\end{array}$ & $\begin{array}{c}\% \\
\text { abnormal }\end{array}$ & $\begin{array}{c}\% \\
\text { BOT } \\
\end{array}$ & $\begin{array}{c}\% \\
\text { SUR } \\
\end{array}$ & $\begin{array}{c}\% \\
\text { ERR } \\
\end{array}$ \\
\hline \multirow[t]{5}{*}{ nAg1 colloid } & 0 & 100 & 0 & 0 & 0 & 0 \\
\hline & 0.001 & 100 & 0 & 0 & 0 & 0 \\
\hline & 0.002 & 0 & 100 & 0 & 0 & 100 \\
\hline & 0.003 & 0 & 100 & 0 & 5.55 & 94.44 \\
\hline & 0.004 & 0 & 100 & 9.9 & 0 & 90.09 \\
\hline \multirow[t]{9}{*}{ nAg2 colloid } & 0 & 100 & 0 & 0 & 0 & 0 \\
\hline & 0.001 & 73.34 & 26.66 & 26.66 & 0 & 0 \\
\hline & 0.00125 & 58.63 & 41.37 & 34.48 & 6.89 & 0 \\
\hline & 0.0015 & 55.56 & 44.44 & 30.7 & 13.74 & 0 \\
\hline & 0.00175 & 48.7 & 51.3 & 43.61 & 7.69 & 0 \\
\hline & 0.002 & 57.36 & 42.64 & 26.9 & 15.74 & 0 \\
\hline & 0.00225 & 66.93 & 33.07 & 20.38 & 12.69 & 0 \\
\hline & 0.0025 & 55.56 & 44.44 & 44.44 & 0 & 0 \\
\hline & 0.00275 & 66.67 & 33.33 & 33.33 & 0 & 0 \\
\hline \multirow{7}{*}{$\begin{array}{c}n A g 3 \\
\text { suspension }\end{array}$} & 0 & 100 & 0 & 0 & 0 & 0 \\
\hline & 0.1 & 68.98 & 31.02 & 0 & 3.44 & 27.58 \\
\hline & 0.125 & 71.43 & 28.56 & 17.85 & 10.71 & 0 \\
\hline & 0.15 & 73.07 & 26.92 & 26.92 & 0 & 0 \\
\hline & 0.175 & 73.69 & 26.3 & 15.78 & 10.52 & 0 \\
\hline & 0.2 & 70 & 30 & 30 & 0 & 0 \\
\hline & 0.225 & 73 & 27 & 27 & 0 & 0 \\
\hline \multirow[t]{9}{*}{$\mathrm{AgNO}_{3}$ solution } & 0 & 100 & 0 & 0 & 0 & 0 \\
\hline & 0.001 & 93.34 & 6.66 & 6.66 & 0 & 0 \\
\hline & 0.001275 & 86.67 & 13.33 & 6.66 & 6.66 & 0 \\
\hline & 0.00155 & 86.67 & 13.33 & 13.33 & 0 & 0 \\
\hline & 0.001825 & 78.27 & 21.73 & 17.39 & 4.34 & 0 \\
\hline & 0.0021 & 54.46 & 45.54 & 22.77 & 22.77 & 0 \\
\hline & 0.002375 & 57.15 & 42.85 & 42.85 & 0 & 0 \\
\hline & 0.00265 & 0 & 100 & 70 & 30 & 0 \\
\hline & 0.002925 & 0 & 100 & 90 & 10 & 0 \\
\hline
\end{tabular}

to the water surface or the bottom. In nAg1, the most common effect was ERR, while in nAg2, the Daphnia were mostly on the bottom or near the surface; so it seemed that $\mathrm{nAg} 2$ had a more severe effect on the Daphnia than nAg1. In the case of nAg3, which was more effective than $\mathrm{nAg} 1$ and $\mathrm{nAg} 2$ at higher concentrations, BOT was the most common abnormal behavior. In this regard, Strigul et al. [51] showed that Daphnia exposed to $\mathrm{TiO}_{2}$ nanoparticles were significantly slower after $24 \mathrm{~h}$ than the control Daphnia.

\section{Conclusion}

This study investigated the acute toxicity of three types of silver nanoparticles and $\mathrm{AgNO}_{3}$ in Daphnia magna.
The experimental results revealed that the different types of nanoparticles and silver ions produced distinct dose-dependent mortalities. In particular, the toxicity of the nano silver powder dispersed by sonication was lower than that of the colloidal silver nanoparticles. Therefore, the results suggested that the toxic responses were related more to the chemical characteristics and aggregation of the different nanoparticles. Future studies will investigate the chronic toxicity of different silver nanoparticles using D. magna.

\section{Acknowledgements \\ This research was supported by Nanomaterial Technology Development Program (Green Nano Technology Development Program) through the National Research Foundation of Korea (NRF) funded by the Ministry of Education, Science and Technology (No. 2011-0020090).}

\section{Author details}

${ }^{1}$ Young Researchers Club, Science and Research Branch, Islamic Azad University, Tehran, Iran. ${ }^{2}$ Institute of Nanoproduct Safety Research, Hoseo University, Asan, Korea. ${ }^{3}$ Institute of Nanoproduct Safety Research, Hoseo University, 165 Sechul-ri, Baebang-myun, Asan 336-795, Korea.

\section{Authors' contributions}

SA, SAJ, JHL, YSK, YBJ, HJC and MCM performed all necessary experiments, SA, SAJ, JHL and IJY analyzed data and wrote manuscript. All authors read and approved the final manuscript.

\section{Competing interests}

The authors declare that they have no competing interests.

\section{Received: 31 December 2011 Accepted: 2 April 2012}

Published: 2 April 2012

\section{References}

1. Woodrow Wilson Database, 2011. Nanotechnology consumer product inventory [http://www.nanotechproject.org/inventories/consumer/ analysis_draft/].

2. Jovanovic' B, Anastasova L, Rowe EW, Zhang Y, Clapp AR, Palic D: Effects of nanosized titanium dioxide on innate immune system of fathead minnow (Pimephales promelas Rafinesque, 1820). Ecotoxicol Environ Saf 2011, 74(7):675-683.

3. Cho KH, Park JE, Osaka T, Park SG: The study of antimicrobial activity and preservative effects of nanosilver ingredient. Electrochemical Acta 2005, 51:956-960.

4. Mohan YM, Lee K, Premkumar T, Geckeler KE: Hydrogel networks as nanoreactors: A novel approach to silver nanoparticles for antibacterial applications. Polymer 2007, 48:158-164.

5. Shahverdi A, Fakhimi A, Shahverdi HR, Minaian S: Synthesis and effect of silver Nanoparticles on the antibacterial activity of different antibiotics against Staphylococcus aureus and Escherichia coli. Nanomedicine: Nanotechnology Biology and Medicine 2007, 3:168-171.

6. Zheng J, Wu X, Wang M, Ran D, Xu W, Yang J: Study on the interaction between silver nanoparticles and nucleic acids in the presence of cetyltrimethylammonium bromide and its analytical application. Talanta 2008, 74:526-532.

7. Blaser SA, Scheringer M, Macleod M, Hungerbühler K: Estimation of cumulative aquatic exposure and risk due to silver: Contribution of nano-functionalized plastics and textiles. Sci Total Environ 2008, 390:396-409.

8. Farkas J, Peter H, Christian P, Gallego Urrea JA, Hassellöv M, Tuoriniemi J Gustafsson S, Olsson E, Hylland K, Thomas KV: Characterization of the effluent from a nanosilver producing washing machine. Environ Int 2011, 37(6):1057-1062.

9. Kaegi R, Sinnet B, Zuleeg S, Hagendorfer H, Mueller E, Vonbank R, Boller M, Burkhardt M: Release of silver nanoparticles from outdoor facades. Environ Pollut 2010, 158(9):2900-2905. 
10. Reijnders $\mathrm{L}$ : The release of $\mathrm{TiO}_{2}$ and $\mathrm{SiO} 2$ nanoparticles from nanocomposites. Polym Degradation Stab 2009, 94:873-876.

11. Baun A, Hartmann NB, Grieger K, Kusk KO: Ecotoxicity of engineered nanoparticles to aquatic invertebrates: a brief review and recommendations for future toxicity testing. Ecotoxicology 2008 17:387-395.

12. OECD Guidelines for the Testing of Chemicals: Daphnia sp., acute Immobilization Test Paris, France: Organization for Economic Cooperation and Development; 2004, Test No. 202.

13. Allen HJ, Impellitteri CA, Macke DA, Heckman JL, Poynton HC, Lazorchak JM, Govindaswamy S, Roose DL, Nadagouda MM: Effects from filtration, capping agents, and presence/absence of food on the toxicity of silver nanoparticles to Daphnia magna. Environ Toxicol Chem 2010, 29(12):2742-2750.

14. Gaiser BK, Biswas A, Rosenkranz P, Jepson MA, Lead JR, Stone V, Tylerd CR, Fernandes TF: Effects of silver and cerium dioxide micro- and nano-sized particles on Daphnia magna. J Environ Monit 2011, 13:1227-1235.

15. Griffitt RJ, Luo J, Ao J, Bonzongo JC, Barber DS: Effects of particle composition and species on toxicity of metallic nanomaterials in aquatic organisms. Environ Toxicol Chem 2008, 27(9):1972-1978.

16. Kennedy A, Hull M, Bednar AJ, Goss J, Gunter J, Bouldin J, Vikesland P, Steevens J: Fractionating Nanosilver: Importance for Determining Toxicity to Aquatic Test Organisms. Environ Sci Technol 2010, 44:9571-9577.

17. Glover CN, Wood CM: Accumulation and elimination of silver in Daphnia magna and the effect of natural organic matter. Aquat Toxicol 2005, 73:406-417.

18. OECD Guidelines for the Testing of Chemicals: Daphnia magne Reproduction Test Paris, France: Organization for Economic Cooperation and Development; 2008, Test No. 211

19. Bhui DK, Bar H, Sarkar P, Sahoo GP, De SP, Misra A: Synthesis and UV-vis spectroscopic study of silver nanoparticles in aqueous SDS solution. $J$ Mol Liq 2009, 145:33-37.

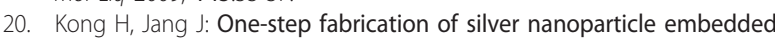
polymer nanofibers by radical-mediated dispersion polymerization. Chem Commun 2006, 28:3010-3012.

21. Petit $C$, Lixon P, Pileni MP: In-situ synthesis of silver nanocluster in AOT reverse micelles. J Phys Chem 1993, 97:12974-12983.

22. Henglein A: Physicochemical properties of small metal particles in solution: microelectrode reactions, chemisorption, composite metal particles, and the atom-to-metal transition. J Phys Chem 1993, 97:5457-5471.

23. Sastry M, Mayya KS, Bandyopadhyay $\mathrm{K}$ : pH-dependent changes in the optical properties of carboxylic acid derivatized silver colloidal particles. Colloid Surf A 1997, 127:221-228.

24. AshaRani PV, Low Kah Mun G, Hande MP, Valiyaveettil S: Cytotoxicity and genotoxicity of silver nanoparticles in human cells. ACS Nano 2008, 3:279-290

25. AshaRani PV, Mun GLK, Hande MP, Valiyaveettil S: Cytotoxicity and genotoxicity of silver nanoparticles in human cells. ACS Nano 2009, 3:279-290

26. Carlson C, Hussain SM, Schrand AM, Braydich-Stolle LK, Hess KL, Jones RL, Schlager JJ: Unique cellular interaction of silver nanoparticles: sizedependent generation of reactive oxygen species. J Phys Chem B 2008, 112:13608-13619.

27. Choi O, Hu ZQ: Size dependent and reactive oxygen species related nanosilver toxicity to nitrifying bacteria. Environ Sci Technol 2008, 42:4583-4588.

28. Liu J, Hurt RH: Ion release kinetics and particle persistence in aqueous nano-silver colloids. Environ Sci Technol 2010, 44:2169-2175.

29. Park SY, Choi J: Geno- and Ecotoxicity Evaluation of Silver Nanoparticles in Freshwater Crustacean Daphnia magna. Environ Eng Res 2010, 15(1):23-27.

30. Kittler S, Greulich C, Diendorf J, Koller M, Epple M: Toxicity of silver nanoparticles increases during storage because of slow dissolution under release of silver ions. Chem Mater 2010, 22:4548-4554.

31. Zhao CM, Wang WX: Importance of surface coatings and soluble silver in silver nanoparticles toxicity to Daphnia magna. Nanotoxicology 2011, doi:10.3109/17435390.2011.579632.

32. Erickson RJ, Brooke LT, Kahl MD, Venter FV, Harting SL, Merkee TP, Spehar RL: Effects of laboratory test conditions on the toxicity of silver to aquatic organisms. Environ Toxicol Chem 1998, 17:572-578.
33. Lemke AE: Interlaboratory comparison acute testing set Springfield, VA: National Technical Information Service; 1981, EPA 600/3-81-005 or PB81160772.

34. Wood CM, La-Point TW, Armstrong DE, Birge WJ, Brauner CJ, Brix KV, Call DJ, Crecelius EA, Davies PH, Gorsuch JW, Hogstrand C, Mahony JD, MCGeer JC, O'Connor TP: Silver in the environment: transport, fate, and effects.Edited by: Andren AW, Bober TW. Pensacola, Florida: SETAC; 2002:25-63.

35. Bianchini A, Bowles K, Brauer CJ, Gorsuch JW, Kramer JR, Wood CM: Evaluation of the effect of reactive sulfide on the acute toxicity of silver (I) to Daphnia magna. Part II: Toxicity results. Environ Toxicol Chem 2002, 21:1294-1300

36. Nebeker A, McAuliffe C, Mshar R, Stevens D: Toxicity of silver to steelhead and rainbow trout, fathead minnows and Daphnia. Environ Toxicol Chem 1983, 2:95-104.

37. Ratte HT: Bioaccumulation and toxicity of Ag compounds: A review. Environ Toxicol Chem 1999, 18:89-108.

38. UN (United Nations): GHS (Globally harmonized system of classification and labelling of chemicals). New York and Geneva 2009.

39. EC: Regulation (EC) No 1272/2008 of the European Parliament and Council of 16 December 2008 on classification, labeling and packging of substances and mixtures. Official Journal of the European Union 2008.

40. EC: Annex VI of Directive 1999/45/EC to consolidated version of directive 67/548/EEC. General classification and labeling requirements for dangerous substances and preparations 1999.

41. Baun A, Sørensen SN, Rasmussen RF, Hartmann NB, Koch CB: Toxicity and bioaccumulation of xenobiotic organic compounds in the presence of aqueous suspensions of aggregates of nano-C60. Aquat Toxicol 2008, 86:379-387.

42. Dabrunz A, Duester L, Prasse C, Seitz F, Rosenfeldt R, Schilde C, Schaumann GE, Schulz R: Biological Surface Coating and Molting Inhibition as Mechanisms of $\mathrm{TiO}_{2}$ Nanoparticle Toxicity in Daphnia magna. PLOS ONE 2011, 6(5):e20112, doi:doi:10.1371/journal.pone.0020112.

43. Edgington AJ, Roberts AP, Taylor LM, Alloy MM, Reppert J, Rao AM, Mao J, Klaine SJ: The influence of natural organic matter on the toxicity of multiwalled carbon nanotubes. Environ Toxicol Chem 2010, 29(11):2511-2518.

44. Heinlaan M, Kahru A, Kasemets K, Arbeille B, Prensier G, Dubourguier HC Changes in the Daphnia magna midgut upon ingestion of copper oxide nanoparticles: A transmission electron microscopy study. Water Res 2011, 45:179-190.

45. Kim KT, Klaine SJ, Cho J, Kim SH, Kim SD: Oxidative stress responses of Daphnia magna exposed to $\mathrm{TiO}_{2}$ nanoparticles according to size fraction. Sci Total Environ 2010, 408:2268-2272

46. Lovern SB, Owen HA, Klaper R: Electron microscopy of gol nanoparticle intake in the gut of Daphnia magna. Nanotoxicology 2008, 2(1):43-48.

47. Roberts AP, Mount AS, Seda B, Souther J, Qiao R, Lin S, Ke PC, Rao AM, Klaine SJ: In vivo biomodification of lipid-coated carbon nanotubes by Daphnia magna. Environ Sci Technol 2007, 41(8):3025-3029.

48. Rosenkranz P, Chaudhry Q, Stone V, Fernandes TF: A comparison of nanoparticle and fine particle uptake by Daphnia magna. Environ Toxicol Chem 2009, 28(10):2142-2149.

49. Zhu X, Zhu L, Chen Y, Tian S: Acute toxicities of six manufactured nanomaterial suspensions to Daphnia magna. J Nanopart Res 2009, 11:67-75.

50. Zhu X, Chang Y, Chen Y: Toxicity and bioaccumulation of $\mathrm{TiO}_{2}$ nanoparticle aggregates in Daphnia magna. Chemosphere 2010, 78:209-215.

51. Strigul N, Vaccari L, Galdun C, Wazne M, Liu X, Christodoulatos C, Jasinkiewicz K: Acute toxicity of boron, titanium dioxide, and aluminum nanoparticles to Daphnia magna and Vibrio fischeri. Desalination 2009, 248:771-782.

doi:10.1186/1477-3155-10-14

Cite this article as: Asghari et al:: Toxicity of various silver nanoparticles compared to silver ions in Daphnia magna. Journal of Nanobiotechnology 2012 10:14. 